\title{
The Relationship between Healthcare Organizational Culture and Nurses' Empowerment
}

\author{
Doha E. Harhash ${ }^{1}$, Hayam A.El $\operatorname{shrief}^{1} \&$ Manal Z. Ahmed ${ }^{1}$ \\ ${ }^{1}$ Nursing Administration, Faculty of Nursing, Menoufia University, Egypt \\ Correspondence: Manal Zeinhom Ahmed, Professor of Nursing Administration, Nursing Administration, Faculty \\ of Nursing, Menoufia University, Egypt.
}

Received: November 10, 2021

Accepted: December 20, 2021

Online Published: December 31, 2021

doi:10.20849/ijsn.v6i4.975

URL: https://doi.org/10.20849/ijsn.v6i4.975

\begin{abstract}
Background: Nowadays, healthcare organizations are affected by changes and reforms, thus new challenges arise for nurses. Nurses need to have the power to achieve their personal and organizational goals. Furthermore, healthcare organizational culture shapes the organization and provides a complex understanding of crucial organizational factors that affect nurses' empowerment.

Aim: Identify the relationship between healthcare organizational culture and nurses' empowerment at hospital setting.

Methods: Descriptive correlational research design was used. A convenient sample of 225 nurses was recruited from University Hospital in the Delta of Egypt. Denison Organizational Culture Survey (DOCS), the Condition of Work Effectiveness Questionnaire (CWEQ-II), the Psychological Empowerment Instrument were used to collect data for the current study. Results: There were a strong healthcare organizational culture among study sample, moderate level of structure empowerment, and moderate level of psychological empowerment. Conclusion: There were positive correlations between healthcare organizational culture, structural, and psychological empowerment. There was a positive correlation between structure and psychological empowerment. Only gender that did not vary with psychological empowerment. Sustaining a strong healthcare organizational culture enhances structure and psychological empowerment among nurses.
\end{abstract}

Keywords: healthcare, nurses, organizational culture, psychological, structure empowerment

\section{Introduction}

Organizational development depends on analysis and identification of the factors that lead to organizational effectiveness. Healthcare organizations and managers are willing to get nurses commitment, which leads to improve productivity. Hospitals' management would like to introduce nurses with norms, values and goals of the hospitals which are important to understand healthcare organizational culture. It is the responsibility of the management to introduce healthcare organizational culture to its nurses that will assist nurses to get familiar with the system of the organization. Interests in healthcare organizational culture from human resource management and performance point of views stems from the fact that organizational culture was perceived to offer a non-mechanistic, flexible and imaginative approach to understand how organizations work (Brown, 2015).

Organizational culture refers to the beliefs, ideologies, and principles and values those individuals of an organization share. This culture is a determining factor in the success of the organization. Organizational culture has the potential to enhance organizational performance, job satisfaction, and enhance the sense of certainty about problem solving. If an organizational culture becomes incongruent with the changing expectations of internal and/or external stakeholders, the organization's effectiveness can decline (Beidas, et al, 2018).

Organizational culture has the potential to enhance organizational performance, nurses' job satisfaction, and the sense of certainty about problem solving. The critical role of culture can improve the ability of organization members to innovate. Also, possession of positive cultural characteristics provides the organization with the necessary ingredients to solve problem with creativity (Kamel \& Aref, 2017). The organizational culture consisted of several factors including internal communication, work balance, leadership style, professional growth, employee satisfaction, reward system, and organizational performance. When any of these factors are compromised, it can negatively affect organization's productivity and profits (Maartje \& Josef, 2020). 
Organizational culture is the system of shared actions, values, and beliefs that develop within an organization and guides the behavior of its members". Organizational Culture is a system for delivery of the value and confidence in developing organizations and as guidance for pretending to members of an organization. Organizational culture is shared values and beliefs that underlie organizational identity (Olin,et al,2019).

Social scientists have explored the notion of healthcare organizational culture as a perspective in organizational theory over the past decades. Scott and Richard (1987) identified five primary culture typologies: stable, reactive, anticipating, exploring, and creative. Hampden-Turner (1990) used four types to describe healthcare organizational culture: role, power, task and atomistic cultures

Nowadays, healthcare organizations are affected by changes and reforms so, new challenges arise for nurses. Nurses need to have power in order to achieve their personal and organizational goals. Power and its exercise are incorporated into the concept of empowerment. Thus, being empowered plays an important role in providing nursing leadership, as it enables nurses to perform their everyday tasks more effectively and in a meaningful way. Furthermore, there has been an interest in research on organizational culture because it shapes the organization and provides a complex understanding of organizational factors such as empowerment (Gunawan \& Aungsuroch, 2017).

Empowerment is critical when enhancing the working environment and is suggested to be an effective means for improvement (Li. et al, 2018). Empowerment in nursing has become noticeable and important. Thus, a need to investigate the phenomenon of nursing empowerment has arisen. Moreover; an interest has emerged in the study of organizational aspects such as culture and climate, which are critical for the success and performance of the organization. Organizational culture shapes the organization and provides complex perceptions of organizational factors like empowerment (Pradhan, et al, 2017).

Nursing empowerment means the ability to effectively motivate and mobilize self and others to accomplish positive outcomes in nursing practices in work environment. Nursing empowerment is instilling a sense of power by granting decision-making authority, creating opportunities to influence decisions, and providing ability to make choices by nurses (Laschinger,et al, 2014).

Empowerment in nursing can mean either arising from the environment or developing from one's psychological state. It can either be structural or psychological. Psychological empowerment was defined as individual's cognitive state characterized by a sense of perceived control, competence and goal internalization. It includes developing the ability to access and control resources, influence and decision making, awareness of freedom, choice, and act with individual confidence. Psychological empowerment has four dimensions: meaning, competence, self-determination, and impact. While structure empowerment is the ways in which the workplace environment supports professional engagement, commitment to professional development, teaching and role development, commitment to community, and recognition of nurses. Structure empowerment has four dimensions: individual involvement, decision power, influence and control over job and environment (Meng, et al, 2016).

There is some evidence that organizational culture and empowerment are connected. According to Fan et al. (2016), structural empowerment promotes managers to undertake special actions for creating an appropriate work environment by providing workers with access to the following empowering structures proposed by Kanter (1993): access to information, support, resources, opportunities to grow, and formal and informal power. Moreover, Laschinger, et al (2014) considered that the psychological empowerment in an organization can be improved with the presence of an appropriate organizational culture in the workplace.

\subsection{Significance of the Study}

An understanding of culture is very important for studying organizational growth and development because it gives an organization a strong competitive advantage. The significance of culture is determined by the existence of a corporate culture that guides behaviors and actions within a group. The role of the nurse manager is highlighted in the creation of an empowering work environment, and having an impact on nurses' perceptions of their own empowerment (Hagerman, 2017).

Organizational culture affects the way nurses interact with each other's, with clients, and with stakeholders. Without the making use of appropriate organizational culture, productivity of the organization will be reduced. Thus, a strong culture can be a stimulus for the empowerment of nurses or limited their yield.

Nurses become psychologically empowered when they perceive high structural empowerment, that lead to positive work behaviors and attitudes such as job satisfaction, commitment, trust and low burnout can be achieved. Therefore, the current study aimed to identify the relationship between healthcare organizational 
culture and nurses' empowerment.

\subsection{Aim of the Study}

This study aimed to identify the relationship between healthcare organizational culture and nurses' empowerment at the hospital setting.

\subsection{Research Hypotheses}

1). There is a positive correlation between healthcare organizational culture and nurses' structure and psychological empowerment.

2). There is a correlation between structure and psychological empowerment.

\section{Conceptual Model}

To identify the relationship between healthcare organizational culture and nurses' empowerment at the hospital setting.

Denison's model of organizational culture was adopted as a framework for this study. The reasons for adopting this model are: the model was built on how empowerment is affected by organizational culture, the model is applied in case of organizational change as it determines components of organizational culture that require change, it also test groups' behaviors, it has a direct impact on organizational culture and provides a novel framework over other organizational culture models, and it has been extensively used by various organizations to evaluate organizational culture.

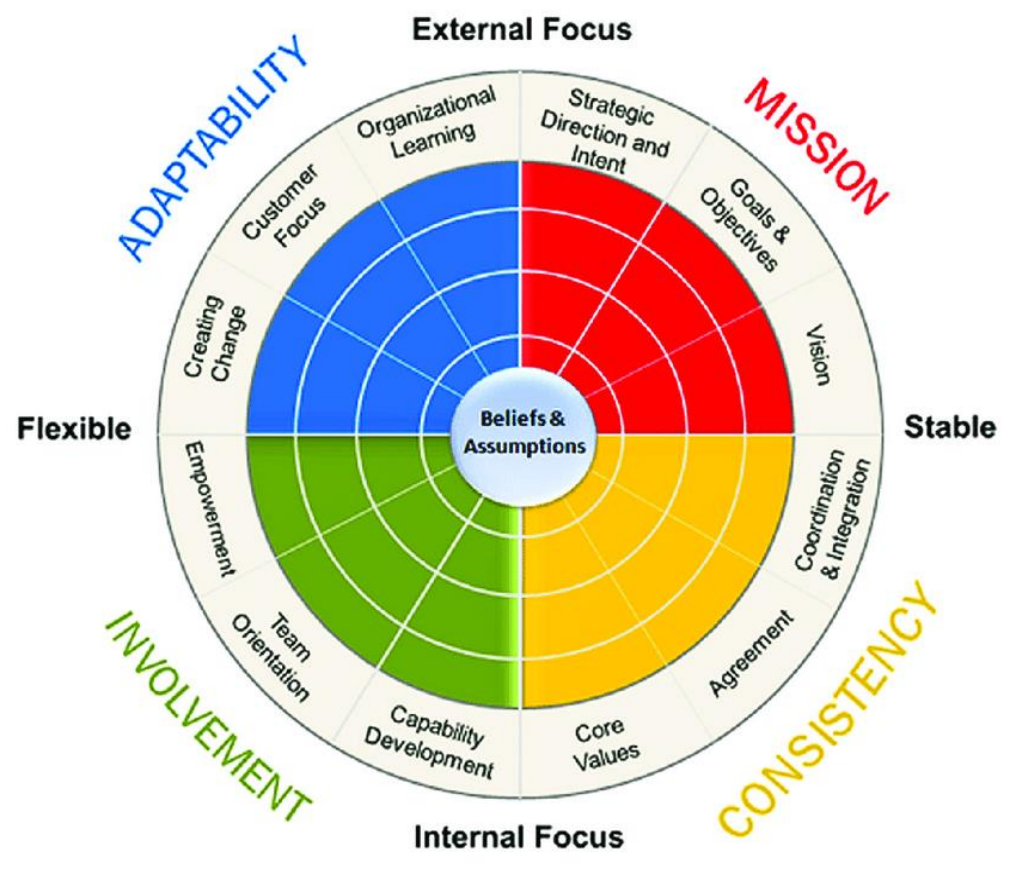

Figure 1. Denison model of organizational culture (1990)

The model includes four key cultural traits: Involvement, consistency, adaptability, and mission. The underlying beliefs and assumptions of any organizational culture result in organizational practices which is called behavioral patterns. These patterns are observable and represented by the four key traits Denison model consulting has identified four key drivers of high performance, improving quality, safety, retention, profitability, and empowerment (mission, adaptability, involvement and consistency) (Denison,1990). This model in congruence with data collection tools that used in current study. 


\section{Methodology}

\subsection{Design}

The study adopted descriptive correlational research design.

\subsection{Setting}

The study was conducted in different departments in one of University Hospital in the Delta of Egypt, included were critical care units, inpatient departments, and outpatient clinics.

\subsection{Sampling}

A convenient sampling technique was used in the current study.. The sample size was calculated utilizing G Power program, with a power of (0.95), alpha of (0.05), and a medium effect size. The minimum sample size required for Pearson correlation coefficient analysis was 198 participants. The total sample size was increased to 225 nurses to avoid the negative impact of attrition. Both male and female nurses who had at least one year of experience can read and understand English and accepted to participate in this study were invited to be part of the research. These inclusion criteria grantees that the participant has the ability to assess their healthcare organizational culture and express if they were empowered in their work environment or not.

\subsection{Ethical Consideration}

Official steps were taken to obtain permission to conduct the study at the previously mentioned setting. Written approval was obtained from the medical and nursing authority after explanation of the aim of the study and study procedures. The respondents' rights were protected by ensuring voluntary participation; so that informed consent was obtained by explaining the purpose, nature, study procedures, and potential benefits of the study. The respondents were assured that the data will be treated as strictly confidential.

\subsection{Data Collection Tools}

Three different tools were used for data collection in addition to study sample demographic characteristics of study sample such as: Age, gender, educational qualification, years of experience, marital status and department will be considered in the current study.

I: Denison Organizational Culture Survey (DOCS) (Mobley, et al, 2005). Which consists of 12 items measure the four main culture traits which include: involvement ( 3 items), consistency ( 3 items), adaptability ( 3 items) and mission (3items). The instrument uses five point likert scale ranging from (1-5) which indicates: (1=strongly disagree, to $5=$ strongly agree). Total score is $(12-60)$ a score of $(<60 \%)$ equal $(12-35)$ indicates weak healthcare organizational culture, and a score of $(\geq 60 \%)$ equal (36-60) indicates strong healthcare organizational culture. The instrument showed strong Cronbach alpha reliability for the total subcategory as follow (involvement, consistency, adaptability, and mission) $(0.94,0.94,0.92$ and 0.96$)$ respectively, in the current study Cronbach alpha reliability was (involvement, consistency, adaptability, mission, and total healthcare organizational culture) $(0.92,0.93,0.82,0.89$ and 0.96$)$.

To measure nurses' empowerment two tools were used to measure both structure and psychological empowerment.

II: The Condition of Work Effectiveness Questionnaire (CWEQ-II) was used to measure staff nurses' perception of their access to six work structures empowerment (Kanter, 1977) The scale consisted of 23 items which measure six separate but interrelated dimensions as the following: support (5 items), information ( 3 items), resources ( 3 items), opportunity ( 6 items), formal power ( 3 items) and informal power ( 3 items). The instrument uses a five point likert scale (1-5) which indicates: $(1=$ never to $5=$ a lot). The Score range is between (23 and 115). Higher scores represent stronger perceptions of working in an empowered work environment. Scores ranging from (23to 51) are described as low levels of empowerment, (52to 83) as moderate levels of empowerment, and (84 to 115) as high levels of empowerment. Cronbach alpha reliabilities for the CWEQ-II ranges from ( 0.79 to 0.82$)$, and ( 0.71 to 0.90$)$ for the subscales. In the current study (support information, resources, opportunity, formal power, informal power and the total score of structures empowerment). (0.89, $0.92,0.90,0.89,0.74,0.92$ and 0.96 ).

III: The Psychological Empowerment tool was designed by Thomas, \& Velthouse (1990) to measure the four dimensions of psychological empowerment. The scale consists of 12 statement measure separate but interrelated dimensions: meaning ( 3 items), competence ( 3 items), self- determination ( 3 items) and impact ( 3 items). The instrument uses seven point likert scale (1-7): $(1=$ very strongly disagree, $2=$ strongly disagree, $3=$ disagree, $4=$ neither agree nor disagree, $5=$ agree, $6=$ strongly agree, $7=$ very strongly agree). Average of subscale scores range from (12 to 84). Higher scores represent stronger perceptions of empowered work environment. Scores ranging 
from (12 to 34) are described as low level of empowerment, (35 to 59) as moderate level of empowerment, and (60 to 84 ) as high level of empowerment. Cronbach alpha reliability in the original instrument ranges from (.62 to .74) for the total scale and from (.79 to .85) for the subscales, in the current study (meaning, competence, self-determination, impact and total score of Psychological Empowerment) (0.95, 0.91, 0.96, 0.97and 0.94).

\subsection{Date Collection and Procedures}

Data collection lasted from three months started from October to Desember2019. The tools of the study were distributed to expertise to determine it clearly, ordering, sequence and content validity. Then send tools to translation office to translate it into Arabic then send it to another translation office to retranslate it into English and compare two English tools to determine clarity of statements. Then take the acceptance of tools distribution, before beginning to collect data from the study subjects. Data was collected in the morning, afternoon and night shifts and subjects fill the questionnaire in the presence of the investigator to ascertain all questions was answered. The time required for each nurse to fill the questionnaire was estimated to be 10-15 minutes.

\subsection{Statistical Analysis}

Descriptive statistics: were expressed as number and percentage for nominal data, or mean and standard deviation for ordinal data.

For comparison among variables t- test was used for comparison between two groups, and ANOVA (F) test was used for comparison between more than two groups. If quantitative data was not normally distributed, Mann-Whitney test (non-parametric test) was used for comparison between two means not normally distributed, and Kruskal-Wallis test was used for comparison between three means of not normally distributed quantitative variables. Qualitative data was analyzed by chi-square $(\chi 2)$ test.

\section{Results}

In relation to demographic characteristics of the study sample: The highest percentage of study sample aged between 20 to $<30$ years $(47.6 \%)$ with mean age of $(27.5 \pm 2.4)$. The majority of study sample was female (78.7\%). More than one third of them had Associate degree in nursing (35.6\%). Most of study sample worked in closed units (59.1\%). As regards to marital status the majority of them were married (78.7\%). Concerning experience; the highest percentage of nurses were 5 to less than 10 years of experience $(30.2 \%)$, with mean of $(7.5 \pm 1.2)$ years of experience.

Table 1 showed percentage distribution and mean score of healthcare organizational culture's subscales more than half of study sample had strong organizational culture with high mean score for involvement subscale $(11.1 \pm 3.2)$ while the lowest mean score was for mission subscale (10.1 13.2$)$.

Table 1. Percentage distribution and mean score of healthcare organizational culture's subscales $(\mathrm{N}=225)$

\begin{tabular}{lcccccc}
\hline $\begin{array}{l}\text { Organizational culture's } \\
\text { subscales and the total score }\end{array}$ & Rang & \multicolumn{2}{c}{ Weak } & \multicolumn{2}{c}{ Strong } & \multicolumn{2}{c}{ Total mean score } \\
\cline { 3 - 7 } & & No & $\%$ & No & $\%$ & M \pm SD \\
\hline Involvement & $(3-15)$ & 40 & 17.8 & 185 & 82.2 & $11.1 \pm 3.2$ \\
Consistency & $(3-15)$ & 47 & 20.9 & 178 & 79.1 & $10.4 \pm 3.3$ \\
Adaptability & $(3-15)$ & 34 & 15 & 191 & 85 & $10.7 \pm 2.9$ \\
Mission & $(3-15)$ & 58 & 25.8 & 167 & 74.2 & $10.1 \pm 3.2$ \\
\hline Total score groups & $(12-60)$ & 91 & 40 & 134 & 60 & $42.3 \pm 11.8$ \\
\hline
\end{tabular}

Table 2 showed percentage distribution and mean score of work structures' empowerment subscales. The table indicated that majority of study sample had moderate work structure empowerment with high mean score was opportunity $(17.7 \pm 4.5)$ while the low mean score was information $(6.9 \pm 3.2)$. 
Table 2. Percentage distribution and level of nursing perception regarding work structures empowerment' subscales $(\mathrm{N}=225)$

\begin{tabular}{lcccccccc}
\hline \multirow{2}{*}{$\begin{array}{l}\text { Work structure empowerment } \\
\text { subscales }\end{array}$} & \multirow{2}{*}{ Range } & No & $\%$ & No & $\%$ & No & $\%$ & M \pm SD \\
\cline { 3 - 9 } & $(5-25)$ & 71 & 31.6 & 118 & 52.4 & 36 & 16 & $13.9 \pm 4.5$ \\
\hline Support & $(3-15)$ & 123 & 54.7 & 64 & 28.4 & 38 & 16.9 & $6.9 \pm 3.2$ \\
Information & $(3-15)$ & 63 & 28 & 116 & 51.6 & 46 & 20.4 & $8.6 \pm 3.1$ \\
Resources & $(6-30)$ & 61 & 27.1 & 105 & 46.7 & 59 & 26.2 & $17.7 \pm 4.5$ \\
Opportunity & $(3-15)$ & 84 & 37.3 & 131 & 58.3 & 10 & 4.4 & $7.3 \pm 2.5$ \\
Formal power & $(3-15)$ & 58 & 25.8 & 100 & 44.4 & 67 & 29.8 & $9.4 \pm 3.6$ \\
Informal power & $(23-115)$ & 81 & 36 & 101 & 44.9 & 43 & 19.1 & $63.9 \pm 19.5$ \\
\hline Total score groups & & & & & & & &
\end{tabular}

Table 3 showed distribution and mean score of work psychological' empowerment subscales. Majority of study sample had moderate work psychological empowerment with high mean score for meaning (17.2 \pm 2.9 ), while the lowest mean score was for self-determination (13.0 \pm 4.1$)$.

Table 3. Percentage distribution and level of nursing perception regarding psychological work empowerment' subscales $(\mathrm{N}=225)$

\begin{tabular}{lcccccccc}
\hline \multirow{2}{*}{$\begin{array}{l}\text { psychological work } \\
\text { empowerment' subscales }\end{array}$} & \multirow{2}{*}{ Range } & \multicolumn{2}{c}{ Low } & \multicolumn{2}{c}{ Moderate } & \multicolumn{2}{c}{ High } & Total \\
\cline { 3 - 9 } & & No & $\%$ & No & $\%$ & No & $\%$ & M \pm SD \\
\hline Meaning of work & $(3-21)$ & 2 & 0.9 & 77 & 34.2 & 146 & 64.9 & $17.2 \pm 2.9$ \\
Competence of work & $(3-21)$ & 2 & 0.9 & 94 & 41.8 & 129 & 57.3 & $16.6 \pm 2.5$ \\
Self determination & $(3-21)$ & 16 & 7.1 & 152 & 67.6 & 57 & 25.3 & $13.0 \pm 4.1$ \\
Impact & $(3-21)$ & 25 & 11.1 & 134 & 59.6 & 66 & 29.3 & $13.1 \pm 4.1$ \\
\hline Total score groups & $(12-84)$ & 5 & 2.2 & 113 & 50.2 & 107 & 47.6 & $59.9 \pm 11.3$ \\
\hline
\end{tabular}

Table 4 demonstrated that there were high statistical positive correlation between organizational culture, structural empowerment, psychological empowerment and grand total of empowerment.

Table 4. Correlation coefficient between total score of organizational culture, total score of structural empowerment, total score of psychological empowerment, and grand total of empowerment $(\mathrm{N}=225)$

\begin{tabular}{llllllll}
\hline \multirow{2}{*}{ Items } & \multicolumn{2}{c}{$\begin{array}{c}\text { Structural } \\
\text { empowerment }\end{array}$} & \multicolumn{2}{c}{$\begin{array}{c}\text { Psychological } \\
\text { empowerment }\end{array}$} & \multicolumn{2}{c}{$\begin{array}{c}\text { Grand total of } \\
\text { empowerment }\end{array}$} \\
\cline { 2 - 8 } & $\mathrm{R}$ & $\mathrm{P}$ & $\mathrm{R}$ & $\mathrm{P}$ & $\mathrm{R}$ & $\mathrm{P}$ \\
\hline Total score of organizational culture & 0.67 & $0.0001^{* *}$ & 0.53 & $0.0001^{* *}$ & 0.66 & $0.0001^{* *}$ \\
\hline
\end{tabular}

Figure 1 showed the positive significant association between total score of psychological empowerment, and total score of structural empowerment among study sample $(r=0.71, \mathrm{P}<0.0001)$. 


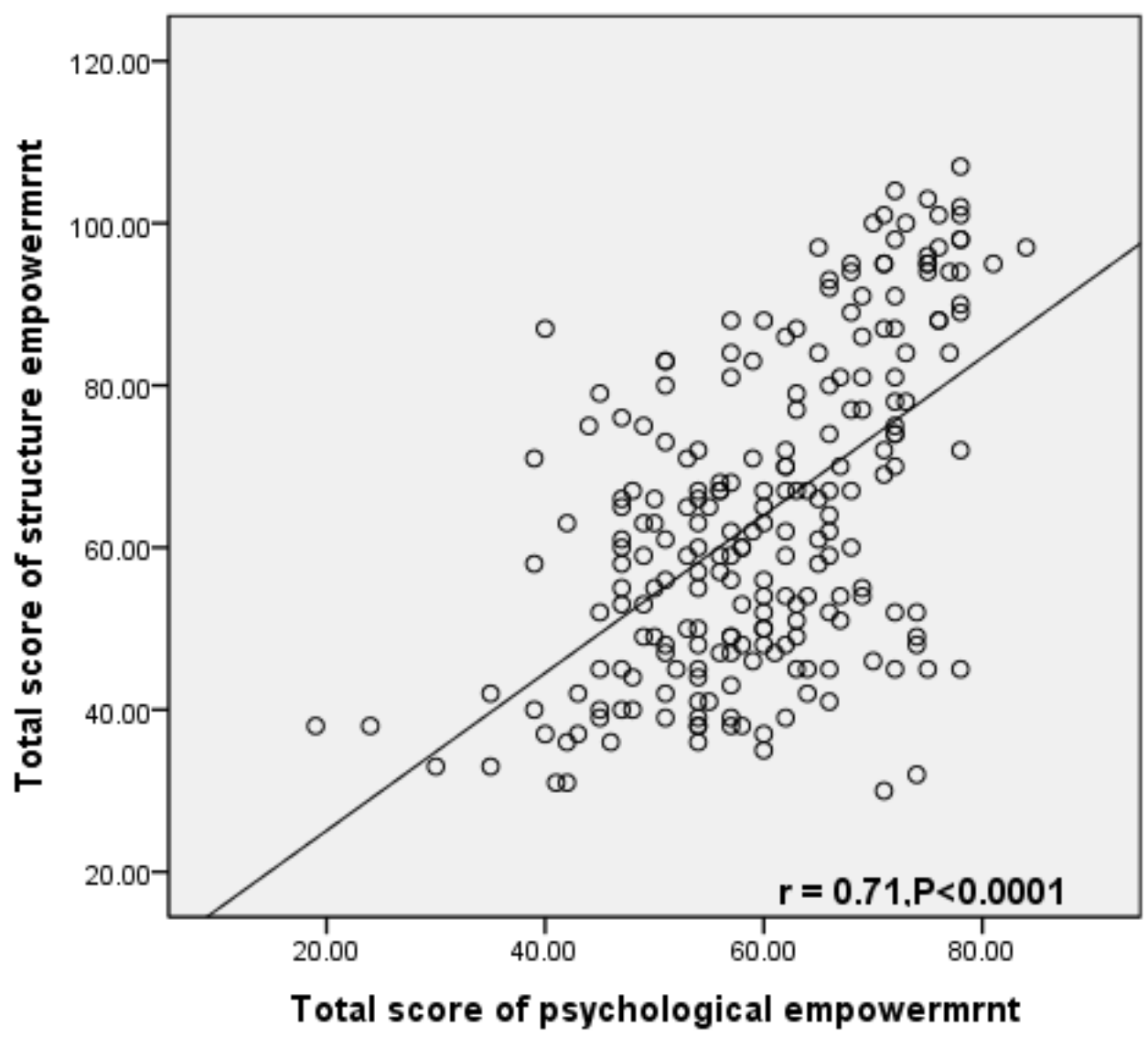

Figure 1. Correlation coefficient between total score of psychological empowerment, and total score of structural empowerment among study sample

Table 5 demonstrated the relationship between the nurses' demographic characteristics and their total perception score of healthcare organizational culture, structural empowerment, and psychological empowerment .This table illustrated that there were high statistical significance between healthcare organizational culture, structural empowerment, and psychological empowerment and study sample demographic characteristics such as age, marital status, qualification, experience except gender was high statistical significance with healthcare organizational culture and structural empowerment only.

Table 5. Relation between the nurses' demographic characteristics and their total perception score about healthcare organizational culture, structural empowerment, and psychological empowerment $(\mathrm{N}=225)$

\begin{tabular}{lccc}
\hline $\begin{array}{l}\text { Demographic } \\
\text { Characteristics }\end{array}$ & $\begin{array}{c}\text { Organizational } \\
\text { culture }\end{array}$ & $\begin{array}{c}\text { Structural } \\
\text { empowerment }\end{array}$ & $\begin{array}{c}\text { Psychological } \\
\text { empowerment }\end{array}$ \\
\cline { 2 - 4 } & $\mathrm{M} \pm \mathrm{SD}$ & $\mathrm{M} \pm \mathrm{SD}$ & $\mathrm{M} \pm \mathrm{SD}$ \\
\hline Age & $39 \pm 11.5$ & $56.4 \pm 15.4$ & $55.3 \pm 9.3$ \\
$20-<30$ & $41.9 \pm 11.8$ & $63.1 \pm 18.4$ & $60.3 \pm 11.5$ \\
$30-<40$ & $49 \pm 8.1$ & $78.4 \pm 18.1$ & $68.2 \pm 8.6$ \\
$40-<50$ & $54.7 \pm 4.3$ & $93.8 \pm 10.6$ & $75.2 \pm 3.8$ \\
$\quad \geq 50$ & $12.9 / 0.000^{* *}$ & $29.6 / 0.000^{* *}$ & $26.9 / 0.000^{* *}$
\end{tabular}

Gender 


\begin{tabular}{|c|c|c|c|}
\hline $\begin{array}{l}\text { Demographic } \\
\text { Characteristics }\end{array}$ & $\begin{array}{c}\text { Organizational } \\
\text { culture }\end{array}$ & $\begin{array}{c}\text { Structural } \\
\text { empowerment }\end{array}$ & $\begin{array}{l}\text { Psychological } \\
\text { empowerment }\end{array}$ \\
\hline & $\mathrm{M} \pm \mathrm{SD}$ & $\mathrm{M} \pm \mathrm{SD}$ & $\mathrm{M} \pm \mathrm{SD}$ \\
\hline Male & $35.5 \pm 15.4$ & $56.7 \pm 19.3$ & $59.3 \pm 10.3$ \\
\hline Female & $44.2 \pm 9.8$ & $65.9 \pm 19.2$ & $60.1 \pm 11.6$ \\
\hline $\mathrm{T} / \mathrm{P}$ & $4.7 / 0.000 * *$ & $2.9 / 0.004 * *$ & $0.42 / 0.67$ \\
\hline \multicolumn{4}{|l|}{ Marital status } \\
\hline Married & $43.9 \pm 10.8$ & $66.1 \pm 19.6$ & $61.8 \pm 11.2$ \\
\hline Un married & $36.3 \pm 13.2$ & $56 \pm 17.5$ & $53 \pm 8.9$ \\
\hline $\mathrm{T} / \mathrm{P}$ & $4.1 / 0.000^{* *}$ & $3.2 / 0.001 * *$ & $5.0 / 0.000^{* *}$ \\
\hline \multicolumn{4}{|l|}{ Qualification } \\
\hline $\begin{array}{l}\text { Technical } \\
\text { diploma }\end{array}$ & $45.8 \pm 11.4$ & $70.9 \pm 20.9$ & $64.6 \pm 12.5$ \\
\hline $\begin{array}{l}\text { Associate } \\
\text { degree }\end{array}$ & $39.5 \pm 12.8$ & $55 \pm 16.3$ & $57.5 \pm 9.7$ \\
\hline Bachelor & $42.2 \pm 10.6$ & $67 \pm 18.1$ & $58.3 \pm 10.7$ \\
\hline $\mathrm{F} / \mathrm{P}$ & $5.4 / 0.005^{* *}$ & $15.4 / 0.000 * *$ & $8.9 / 0.000 * *$ \\
\hline \multicolumn{4}{|l|}{ Experience } \\
\hline $1-<5$ & $37.6 \pm 11.7$ & $57.2 \pm 15.3$ & $54.8 \pm 8.7$ \\
\hline $5-<10$ & $42.4 \pm 11$ & $61.4 \pm 18.6$ & $57.6 \pm 11.7$ \\
\hline $10-<15$ & $40.3 \pm 11.7$ & $56.9 \pm 17.1$ & $58.2 \pm 9.8$ \\
\hline $15-<20$ & $47.3 \pm 11.4$ & $75.4 \pm 17.8$ & $66.9 \pm 9.7$ \\
\hline$\geq 20$ & $50.1 \pm 8.5$ & $83.5 \pm 18.9$ & $72.1 \pm 6.4$ \\
\hline $\mathrm{F} / \mathrm{P}$ & $7.5 / 0.000 * *$ & $15.4 / 0.000 * *$ & $18.5 / 0.000^{* *}$ \\
\hline
\end{tabular}

\section{Discussion}

Healthcare organizational culture is of lifestyle of an organization because the original source of any organization is its human resource, so the employees' performance is affected by culture of this organization. Some research studies consider healthcare organizational culture based on the formation of empowerment. Healthcare organizations can be successful in empowerment processes that are of defined valuable principles. Nursing managers who are aware of the relationship between organizational culture and empowerment among nurses can encourage them to be empowered with the use of their talents, knowledge, skills and experiences (Kamel \& Aref, 2017).

Therefore, the purpose of this study was to identify the relationship between healthcare organizational culture and nurses' structural and psychological empowerment at the hospital setting.

The present study revealed that the majority of study sample had strong healthcare organizational culture. The highest mean score was for" involvement" subscale where the majority of study sample agreed on "work is organized so that each person can see the relationship between his or her job and the goals of the organization". While the lowest mean score was for "mission" subscale where the majority of study sample disagreed on "our strategy leads other organizations to change the way they compete in the field of healthcare.

These outcomes can be rationalized as nursing involvement in an organized work led them to correlate between their tasks and achievement of organizational goals. On the other hand, mission subscale had the lowest score because nursing managers at the top levels did not share their organizational mission with non-managerial nursing personnel.

These results were congruent with Abdullah (2019), who conducted a study about staff nurses' perception toward organizational culture and its relation to innovative work behavior. The results showed that more than 
half of staff nurses had positive perception of healthcare organizational culture.

This result was also on agreement with Zeyada (2018), who conducted a study about the relationship between organizational culture and product innovativeness. The result showed strong organizational culture. Additionally, Egwakhe (2019), conducted a study about organizational culture and its impact on organizational citizenship behavior, the results showed a strong organizational culture too.

The present study also revealed that the majority of study sample had moderate level of perception about work structure empowerment with highest mean score was for" opportunity" subscale where the majority of study sample agreed on "the chance to gain new skills and knowledge on the job". Meanwhile, the lowest mean score was for" information" subscale where the majority of study sample disagreed on "how salary decisions are made for people in position like yours".

From investigator point of view, nurses had moderate level of work structure empowerment because not only professional development opportunities that lead to structure empowerment among nurses in healthcare organization. There are many other factors that affect nurses' work structure empowerment such as proper leadership style of first line nursing managers, proper scheduling, salary, proper nurses' patient ratio and workload. In addition, the informal power, developing relationships within the organization that influence and facilitate organizational work access created empowerment in the work environment for nurses.

Result of the current study was consistent with Trus, et al (2019), who conducted a study to propose a model for nurses' empowerment through characteristics of workplace and management strategies in Iranian hospitals. The result reported that nurses in Iran social security organization hospitals considered their structural empowerment status at a moderate level. This result was also congruent with Bish, et al (2014), who conducted a study about nurse managers' work-related empowerment evaluated in connection to power issues and organizational social context at Tampere University in Finland. The results showed that nurse managers had moderate level of structural empowerment too. Moreover, Willis (2015), studied perceptions of structural empowerment among rural nurse leaders. The study found that nursing leaders had moderate level of structural empowerment as well.

On the contrary, Barden, et al, (2011), conducted a study to compare the level of empowerment between two nursing units in Cleveland clinic. The results revealed that both units were in moderate level of total empowerment. While there was a higher level of all subscales of structure empowerment. Furthermore, a study Saremi, and Nejad, (2013), who conducted a study about empowerment and job satisfaction in associate degree nurse educators. The result reported high level of structural empowerment among nurse educators.

The present study revealed that the majority of study sample had moderate level of work psychological empowerment with highest mean score was for "meaning" subscale where the majority of study sample agreed on "my job activities are personally meaningful to me". While the lowest mean score was for "self-determination" subscale where the majority of study sample strongly disagreed on "I can decide on my own how to go about doing my work" i.e., most nurses do not have the freedom to do their work the way they preferred it.

These results were confirmed by Ibrahim, et al (2014), who conducted a study about nurses' psychological empowerment and perceived autonomy among University and teaching hospitals' nurses. The results reported that most of nurses in university and teaching hospitals perceived a moderate level of psychological empowerment. Additionally, El-Demerdash, and Obied (2016), conducted a study about influence of empowerment on nurses' participation in decision making. The results showed that majority of study sample had a moderate level of psychological empowerment.

On the other hand, Hosni (2014), conducted a study about nurse managers' work-related empowerment and power issues in organizational social context. The results showed that nurse managers perceived a high level of psychological empowerment. Moreover, Ali, et al (2018), conducted study about the effect of empowerment on nurses' organizational commitment. This study showed a lower level of psychological empowerment among nurses.

The result of current study demonstrated that there were high statistical significance and positive correlation among organizational culture, grand total of empowerment scale, structural empowerment, and psychological empowerment.

These results were in congruence with Sotirofski (2014), who conducted a study about the impact of organizational culture on employees' empowerment. The results reported a positive relationship between organizational culture and nurses' empowerment. This study highlighted that the low index of empowerment is due to absence of organizational culture. Without the making use of appropriate organizational culture, nurse 
managers would challenge decline in the productivity of healthcare organizations. Because a suitable culture can be productivity motive, so, healthcare organizational culture induces to nurses how much effort they should do. Thus, a strong culture can be a stimulus for the empowerment of nurse.

On top of that, Jeong (2019) conducted a study about organizational culture impact on psychological empowerment of academic staff and found that organizational culture has a great impact on psychological empowerment of academicians. Likewise, Trus, et al, (2018), conducted a study about exploring the relationships among organizational culture, empowerment, and organizational citizenship behaviors. The findings revealed that all sub-factors of organizational culture such as clan culture, adhocracy culture, and market culture were positively influential of perceived empowerment. Only hierarchy culture that was negatively associated to the perceived level of empowerment.

In addition, Sürücü and Sürücü (2020), who conducted a study about relationship between organizational culture and empowerment from nurse managers' point of view. The findings showed that nurse managers were both structurally and psychologically empowered when the organizational culture was proficient and resistant.

The results of present study showed that there were highly statistically significant differences among all of nurses' demographic characteristics and their total score of healthcare organizational culture for married nurses with 50 years or more and 20 years or more of experience.

These results were congruent with Belias and Koustelios (2014), who conducted a study about organizational culture and demographic characteristics of employees. The result showed that employees' perceptions of organizational culture changes according to gender, age, marital status, work experience and working time with the same manager. These results were also in agreement with El Badawy, et al (2017), who conducted a study about the influence of demographic characteristics of Greek bank employees on their perceptions of organizational culture. The results showed that age and work experience differ among employees' perception of their work culture.

On contrary, Wani (2017), conducted a study about the demographics' effects on organizational culture, organizational citizenship behaviors and job satisfaction among Egyptian and Mexican samples. Results showed no demographic effect on the organizational cultures for gender, age, years of experience and education levels in both Egyptian and Mexican samples.

Moreover, Hendrawijaya (2019), conducted a study about demographic characteristics impact on organizational culture and employee motivation. The study showed that gender and educational levels did not have significant difference among study sample.

The present study showed high statistically significant difference between all of nurses' demographic characteristics and their total score of structural empowerment. Married female nurses who had a bachelor's degree in nursing, aged between 20 to less than 30 years old, and had one to five years of work experience statistically different with organizational structure. The rationale for these results that most of recruited nurses in the university hospital had bachelor's degree in nursing, and were females because male nurses with bachelor's degree in nursing were few as male joined nursing profession recently.

This result was congruent with Rajasekar, et al, (2017), who conducted a study about demographic factors and employees' empowerment. The results showed that there was a relationship between demographic factors and employees' structure empowerment. Furthermore, Al-Kahtani (2012), conducted a study on employees' empowerment with the demographic variables among employees of Union Bank of India. The study found that both age and education were related to employee's structure empowerment .Besides, Meng and Sun (2019), conducted a study on employees' empowerment in Indian corporate sector. The study reflected that gender, age, and job period are related with employee structure empowerment.

The results of the present study showed a high statistically significant differences between all nurses' demographic characteristics and psychological empowerment. There was statistically significant difference among married nurses with bachelor's degree in nursing, had between 20 to less than 30 years old, and work experience of one to less than five years. Only gender was not statistically significant different with psychological empowerment.

These results were congruent with Saputro and Kurniawan (2020), who conducted a study about the impact of psychological empowerment on work engagement among university faculty members in china. The study found that age was also a key variable influencing faculty members' psychological empowerment in which older faculty members had higher psychological empowerment scores. The analysis also revealed significant differences in educational degree in which faculty members with higher educational degrees had higher 
psychological empowerment.

\section{Conclusion}

Study sample had a strong healthcare organizational culture, a moderate level of both work structure empowerment and psychological empowerment. There was also a positive correlation between structure and psychological empowerment.

Consequently, the study implied that strong healthcare organizational culture strongly affects both structure and psychological empowerment among nurses. Therefore, strong healthcare organizational culture should be part of the strategic planning and core values of healthcare organizations to create a strong healthcare organizational culture. Development of understanding between nursing managers, nurses, and enhance intraprofessional and interprofessional nursing collaboration is mandated too. More correlation research studies are needed to ascertain that structural empowerment affects positively psychological empowerment. Repetition of the same study with a larger sample from different healthcare sectors may help in the generalization of results.

\section{References}

Abdullah, N. H. (2019). The Relationship between Organizational Culture and Product Innovativeness. Procedia - Social and Behavioral Sciences, 129, 140-147. https://doi.org/10.1016/j.sbspro.2014.03.659

Ali, A. F., El sayed, S. H., Shazly, M. M., \& AbdElrahman, S. M. (2018). Relationship between Empowerment and Organizational Commitment among Staff Nurses. IOSR Journal of Nursing and Health Science (IOSR-JNHS), 7(1), Ver. IX, 17-24.

Al-Kahtani, N. S. (2012). A study of relationship between demographical variables, organizational structure and social interaction with organizational commitment among employees of Saudi Arab. International Journal of Trade and Commerce, 1(1), 11-22.

Barden, A., Griffin, R., Quinn, M., Donahue, M., \& Fitzpatrick, J. (2011). Shared Governance and Empowerment in Registered Nurses working in a hospital setting. Nursing Administration Quarterly, 35(3), 212-218. https://doi.org/10.1097/NAQ.0b013e3181ff3845

Beidas, R. S., Williams, N. J., Green, P. D., Aarons, G. A., Becker-Haimes, E. M., Evans, A. C., ... Marcus, S. C. (2018). Concordance between administrator and clinician ratings of organizational culture and climate. Administration and Policy in Mental Health and Mental Health Services Research. Adm Policy Ment Health, 45, 142-151. https://doi.org/10.1007/s10488-016-0776-8

Belias, D., \& Koustelios, A. (2014). The influence of demographic characteristics of Greek bank employees on their perceptions of Organizational Culture. International Journal of Human Resource Studies, 4(1), 81. https://doi.org/10.5296/ijhrs.v4i1.5058

Bish, M., Kenny, A., \& Nay, R. (2014). Perceptions of structural empowerment: nurse leaders in rural health services. Journal of Nursing Management, 22, 29-37. https://doi.org/10.1111/jonm.12029

Brown, A. D. (2015). Identities and identity work in organizations. International Journal of Management Reviews, 17, 20-40. https://doi.org/10.1111/ijmr.12035

Brown, A. D. (2017). Identity work and organizational identification. International Journal of Management Reviews, 19, 296-317. https://doi.org/10.1111/ijmr.12152

Denison, D. R. (1990). Corporate culture and organizational effectiveness: Is there a similar pattern around the world?. Advance in Global Leadership, 3, 205-227. https://doi.org/10.1111/jonm.12029

Egwakhe, A. J. (2019). Workers Wellbeing and Creative Person: Organizational Culture Effect. International Journal of Innovative Research in Science, Engineering and Technology, 8(9). https://doi.org/10.15680/JJIRSET.2019.0809011

ElBadawy, T. A., Trujillo-Reyes, J. C., Mariam, M., \& Magdy, M. M. (2017). The Demographics' Effects on Organizational Culture, Organizational Citizenship Behavior and Job Satisfaction: Evidence from Egypt and Mexico Business. Management Research, 6(1). https://doi.org/10.5430/bmr.v6n1p28

El-Demerdash, S. M., \& Obied, H. K. (2016). Influence of Empowerment on Nurses' Participation in Decision Making. Journal of Nursing and Health Science, 5(5), Ver. VII, 66-72. https://doi.org/10.9790/1959-0505076672

Fan, Y., Zheng, Q., Liu, S., \& Li, Q. (2016). Construction of a new model of job engagement, psychological empowerment and perceived work environment among Chinese registered nurses at four large university 
hospitals: implications for nurse managers seeking to enhance nursing retention and quality of care. Journal of Nursing Management, 24, 646-655. https://doi.org/10.1111/jonm.12369

Gunawan, J., \& Aungsuroch, Y. (2017). Managerial competence of first-line managers: a concept analysis. International Journal of Nursing Practice, 23(1), 1-7. https://doi.org/10.1111/ijn.12502

Hagerman, H., Hogberg, H., Skytt, B., Wadensten, B., \& Engstrom, M. (2017). Empowerment and performance of managers and subordinates in elderly care: a longitudinal and multilevel study. Journal of Nursing Management, 25, 647-656. https://doi.org/10.1111/jonm.12504

Hampden-Turner, C. (1990). Corporate Culture, from vicious to virtuous cycles. London: The Economist Books Ltd. Retrieved from https://www.amazon.com/Corporate-Culture-Vicious-Vi

Hendrawijaya, A. T. (2019). Demographic Factors and Employee Performance: The Mediating Effect of Employee Empowerment. Media Ekonomi dan Manajemen, 34(2), 116-136. https://doi.org/10.24856/mem.v34i2.962

Hosni, E. K. (2014). Effect of Workplace Civility and Empowerment on Newly Graduated Nurses Organizational Commitment at Hospitals in Assiut City. Doctorate Thesis In Nursing Administration, p. 6, Faculty of Nursing, Assiut university. https://doi.org/10.1111/j.1365-2834.2010.01165.x

Ibrahim, M. M., Abo El-Magd, M. H., \& Sayed, H. Y. (2014). Nurse's psychological empowerment and perceived autonomy in university and teaching hospitals at Menofia Governorate/Egypt. Journal of Nursing Education and Practice, 4(9). https://doi.org/10.5430/jnep.v4n9p59

Jeong, Y. (2019). Exploring Relationships among Organizational Culture, Empowerment, and Organizational Citizenship Behavior in the South Korean. Professional Sport Industry Sustainability Article, 11, 5412. https://doi.org/10.3390/su11195412

Kamel, F., \& Aref, M. (2017). Staff Nurses Perception Toward Organizational Culture and Its Relation to Innovative Work Behavior at Critical Care Units. American Journal of Nursing Science, 6(3), 251-260. https://doi.org/10.11648/j.ajns.20170603.23

Kanter, M. (1977). Men and Women in the corporation. Basic books, NewYourk, 13(3), 471-482. Retrieved from https://www.hbs.edu/faculty/Pages/item.aspx?num=10807

Kanter, R. M. (1993). Men and women of the corporation (2nd ed.). New York, NY: Basic Books.

Laschinger, H. K. S., Nosko, A., Wilk, P., \& Finegan, J. (2014). Effects of unit empowerment and perceived support for professional nursing practice on unit effectiveness and individual nurse well-being: a time-lagged study. International Journal of Nursing Studies, 51, 1615-1623. https://doi.org/10.1016/j.jinurstu.2014.04.010

Laschinger, H. K., Finegan, J., Shamian, J., \& Wilk, P. (2001). Impact of structural and psychological empowerment on job strain in nursing work settings: expanding Kanter's model. JONA: The Journal of Nursing Administration, 31(5), 260-272. https://doi.org/10.1097/00005110-200105000-00006

Li, H., Shi, Y., Li, Y., Xing, Z., Wang, S., Ying, J., Zhang, M., \& Sun., J. (2018). Relationship between nurse psychological empowerment and job satisfaction: a systematic review and meta-analysis. Journal of Advanced Nursing, 74, 1264-1277. https://doi.org/10.1111/jan.13549

Maartje, P., \& Josef, R. (2020). Effect of Motivation, Leadership, and Organizational Culture on Satisfaction and $\begin{array}{lllll}\text { Employee Performance. Journal of Asian } & \text { Finance, 7(8), 577-588. }\end{array}$ https://doi.org/10.13106/jafeb.2020.vol7.no8.577

Meng, L., Jin, Y., \& Guo, J. (2016). Mediating and/or moderating roles of psychological empowerment. Applied Nursing Research, 30, 104-110. https://doi.org/10.1016/j.apnr.2015.11.010

Meng, Q., \& Sun, F. (2019). The Impact of Psychological Empowerment on Work Engagement among University Faculty Members in China. Press Journal of Psychology Research and Behavior Management, 12(6), 151-158. https://doi.org/10.2147/PRBM.S215912

Mobley, W. H., Wang, L., \& Fang, K. (2005). Organizational culture: measuring and developing it in your organization. Harvard Business Review China, March 6.

Olin, S. S., Williams, N., Pollock, M., Armusewicz, K., Kutash, K., Glisson, C., \& Hoagwood, K. E. (2019). Quality indicators for family support services and their relationship to organizational social context. Administration and Policy in Mental Health, 41, 43-53. https://doi.org/10.1007/s10488-013-0499-z 
Pradhan, R. K., Panda, M., \& Jena, L. K. (2017). Transformational leadership and psychological empowerment: the mediating effect of organizational culture in Indian retail industry. Journal of Enterprise Information Management, 30, 82-95. https://doi.org/10.1108/JEIM-01-2016-0026

Rajasekar, D., Sudheer, A. K., \& Reddy, P. R. (2017). A study on employee empowerment in Indian corporate sector. International Journal of Civil Engineering and Technology, 8(11), 268-277. Retrieved from https://iaeme.com/MasterAdmin/Journal_uploads/IJCIET/VOLUME_8_ISSUE_11/IJCIET_08_11_029.pdf

Saputro, A. B., \& Kurniawan, I. S. (2020) Demographic characteristics and psychological empowerment on service orientation: a study in Yogyakarta, Indonesia. Holistica Journal of Business and Public Administration, 11(2), 63-73. https://doi.org/10.2478/hjbpa-2020-0019

Saremi, H., \& Nejad, B. M. (2013). Impact empowerment and job satisfaction Mgmt. Elixir International Journal. Retrieved from https://www.elixirpublishers.com/articles/1396855866_65B\%20(2013)\%2019821-19829.pdf

Saremi, H., \& Nejad, B. M. (2013). Impact of organizational culture on Employees Empowerment Elixir Human Res. Mgmt. Elixir International Journal. Retrieved from https://www.elixirpublishers.com/articles/1396855866_65B\%20(2013)\%2019821-19829.pdf

Scott, R. W. (1987). Organizations: Rational, Natural and Open Systems. Englewood Cliffs, Prentice-Hall. Academy of Management Journal, 38(5), 1442-1465. Retrieved from https://www.researchgate.net/publication/200044687_Organizations_Rational_Natural_and_Open_Systems _International_Edition

Sotirofski, K. (2014). Organizational Culture Impact on Psychological Empowerment of Academic Staff. European Journal of Sustainable Development, 3(2), 119-124. https://doi.org/10.14207/ejsd.2014.v3n2p119

Sürücü, L., \& Sürücü, D. (2020). Organizational Culture and Demographic Characteristics of Employees. Journal of Business Research-Turk, 12(2), 1046-1057. https://doi.org/10.20491/isarder.2020.894

Thomas, K. W., \& Velthouse, B. A. (1990). Cognitive elements of empowerment: an 'interpretive' model of intrinsic task motivation. Academy of Management Review, 15(4), 666-681. https://doi.org/10.2307/258687

Trus, M., Doran, D., Martinkenas, A., Asikainen, P., \& Suominen, T. (2018). Perception of work-related empowerment of nurse managers. Journal of Research in Nursing, 23(4), 317-30. https://doi.org/10.1177/1744987117748347

Trus, M., Galdikiene, N., Balciunas, S., Green, P., Helminen, M., \& Suominen, T. (2019). Connection between organizational culture and climate and empowerment: a perspective of nurse managers. Nursing and Health Sciences, 21(1), 51-62. https://doi.org/10.1111/nhs.12549

Wani, A. (2017). Demographics \& Its Impact on Organizational Culture and Employee Motivation. International Journal of Engineering and Management Research, 7(4).

Willis, C. (2015). Evaluation of Empowerment Levels of the Cleveland Clinlc Nurse, Walden Dissertation and Doctoral Studies. Walden Unive Dissertation Rsity, Scholar Works, College Of Health Science. http://Scholar Works, Walden. U. Edu.

Zeyada, M. (2018). Organizational Culture and its Impact on Organizational Citizenship Behavior. International Journal of Academic Research in Business and Social Sciences, 8(3), 418-429. https://doi.org/10.6007/IJARBSS/v8-i3/3939

\section{Copyrights}

Copyright for this article is retained by the author(s), with first publication rights granted to the journal.

This is an open-access article distributed under the terms and conditions of the Creative Commons Attribution license (http://creativecommons.org/licenses/by/4.0/). 